\title{
Negotiating the Cultural Terrain in Transforming Classrooms-The LEAP MODEL
}

\author{
Lifeas Kudakwashe Kapofu ${ }^{1}$ \\ ${ }^{1}$ Department of Education, Australia \\ Correspondence: Lifeas Kudakwashe Kapofu, Department of Education, Australia. E-mail: lifeask@yahoo.co.uk
}

Received: October 17, 2020

Accepted: November 30, 2020

Online Published: February 20, 2021

doi:10.5539/ies.v14n3p51

URL: https://doi.org/10.5539/ies.v14n3p51

\begin{abstract}
This study recentres the sociocultural in culturally transforming pedagogic settings whilst foregrounding culturally responsive teaching (CRT). Through a protracted anthropological excavation, teachers' experiences in a culturally diverse integrated high school were explored and interpreted vis-à-vis tenets and precepts of CRT. Findings from observation and interviews indicate that the pedagogic settings as structured by the teachers were not attendant to the aspirations of CRT and teacher practices were not reflective of dispositions of CRT. Teachers professed negative experiences of the pedagogic setting, demonstrated and professed limited knowledge of the cultural being of their learners. The findings highlighted the need for micro-context cultural excavations to remedy socioculturally detached teaching. Cognisant of the emergent need for a learning tool, the LEAP model is proposed premised on centering the humanistic world of the learners and the inherent currency in their culture for progressive teaching and learning engagements.
\end{abstract}

Keywords: culture, urban black youth, multicultural classrooms, culturally responsive teaching, the LEAP model

\section{Introduction and Background}

Overtures in accommodating socio-cultural diversity in education have yielded astute legislative frameworks and policy infrastructure for inclusivity worldwide. The inherent conviction in these attempts has been that curriculum reform and its implementation by teachers would suffice to serve as a vehicle for change accommodative of cultural diversity in democratised learning spaces (Kapofu, 2019). Nevertheless, diversity in contemporary classrooms has ushered in a complex reality in which teachers must learn about their culturally diverse learners and evolve ways of harnessing their academic potential (Gilmour, Klieve, \& Li, 2018). However, macro-institutional prescripts have not been the panacea of the history's vestigial challenges from desegregation and decolonisation (Jansen, 2004). Concomitant claims have been that the majority of practising science teachers are underprepared or unprepared to address diversity and incorporate cultural diversity (Gilmour et al., 2018; Howard, 2016) with teachers approaching culturally diverse classrooms with anxiety and doubtful of their competence (Moloney \& Saltmarsh, 2016). To compound the problem teacher education programs are finding exigent existing pre-service teachers' biases (Johnson, 2011). Even with minimal success McAllister and Irvine (2000) indict the generalised approaches to multicultural education programs for failing to recognise that introductory modules to multicultural education do not necessarily provide deeper insights into learners' cultures that the teachers need to succeed. Bennet (2015) posits that efforts at accommodating diversity have also been hamstrung by the hidden curriculum. Implied by Bennet (2015) is that sustainable accommodation of diversity needs to proceed as school interventions that tackle the hidden curriculum.

One vehicle, through which the hidden curriculum is peddled in schools, is culture. Thus, heeding Bennet's (2015) postulates prompts us to rethink how we can develop tools capable of generating cultural knowledge for the creation of learning spaces in which ALL learners will be able to insert themselves democratically into curricula processes. The limited impact of macro-level interventions in optimising learning experiences not only reveals limitations in the system but devolves the responsibility for intervention to the classroom teachers. Teachers and researchers are thus faced with the responsibility of developing strategies, pedagogical tools and technologies critical for operating in contexts characterised by diversity. This responsibility carved the bi-pronged goals of this study.

The study sought to: 
- Explore teachers' experiences in diverse classes and how their practices were attendant to the expectations of culturally responsive teaching.

- Develop a pedagogical tool with utility for learning learners' cultures and concomitantly configure classroom practices.

The second goal was premised on the notion that a certain functional knowledge exists and awaits to be deciphered in multicultural contexts through developing and deploying pedagogical tools that glean the premium in learners' culture and drawing on it in meaningful ways.

\section{Literature Review}

Culture is at the heart of education, whether it is the curriculum, instruction, administration or performance assessment (Gay, 2018). The acquisition, transmission and invention of education are related to culture. Thus, a critical understanding of culture is indispensable in understanding and managing the educational process (Pai, Adler, \& Shadiow, 2006). The need for cultural approaches in teaching emerges from the changing demographics vis-a-vis learner population juxtaposed on the homogeneous teaching force (Ladson-Billings, 1995; Gay, 2018). Secondly, it emanates from the need to steer away from archaic and inappropriate practices of structuring learning for all learners using the same strategies as prescribed by the dominant culture.

Consensus exists among researchers on the indispensability of culture for reformation in education and the promotion of academic success of those socio-culturally marginalised (Goldston \& Nichols, 2009; Johnson, 2011). The teacher as a learning mediator is called upon to mediate learning in a culturally sensitive manner inclusive of showing respect for difference and appropriately contextualising curricula (Gay, 2018). However, historically segregation and colonialism have led to a situation in which very few teachers have any experience of working in classrooms other than those segregated. According to Van Wyk (2002) the ethical imperative for teachers in such contexts is learning how to cater to cultural diversity in their practices. The inherent belief being that curricula cannot be successfully implemented without a knowledge of the learners' being (Van Wyk, 2002) as argued by Howard (2016, p. 1) "We can't teach what we don't know". This statement applies to the knowledge of both the of and about of learners as well as knowledge of the subject matter. The implicit belief being that through knowing and deploying knowledge of their learners in practice teachers circumvent the reductive didacticism of teaching by adopting exciting and exploratory approaches. Such circumvention resonates with explanation of knowing and being which foregrounds the moral dimension of education, that is, education needs to address all facets of the being and free the being to be what it can freely be. Thus, successful teachers within this paradigm master knowledge of both discipline and diversity.

Works that advocate for connections between learners' cultures and school cultures in developing viable pedagogic settings are known in a variety of ways: (i) culturally appropriate (Au \& Jordan, 1981); (ii) culturally congruent (Mohatt \& Erickson, 1981); (iii) culturally responsive (Gay, 2018) and (iv) culturally compatible (Vogt, Jordan, \& Tharp, 1987). For this study, the term culturally responsive teaching (CRT) as put forward by Gay (2018) is used.

Gay (2018) elucidates teaching within the CRT paradigm as having the following characteristics: it acknowledges the legitimacy of the collective cultural heritage of different ethnic groups; it builds bridges of meaningfulness between home and school experiences as well as between academic abstractions and lived sociocultural realities; it uses a variety of instructional strategies that are connected to different learning styles; it teaches learners to know and praise their own and each other's cultural heritages and it incorporates multicultural information, resources, and materials in all the subjects and skills routinely taught in schools. Within this paradigm teachers have knowledge, skills, and disposition to effectively guide diverse groups of children. Teaching is a learning process involving a slow integration of knowledge into practice. The integration of knowledge into practice is reflexive with teachers reflecting on their practices and transforming how they feel and think about their learners.

\section{Methods}

This study followed a naturalistic research approach (Yin, 2017) framed within the interpretivist paradigm. The research was conducted as ethnography (Cruz \& Higginbottom, 2013) in a multicultural urban school, Wingate High School (WHS). The research focused on grade eleven science classes since they were the most culturally diverse in the school.

A multi-method approach was employed in data collection (Brewer \& Hunter, 2006). Data were collected through six observation sessions conducted in the two science classrooms over one school term. Observations were guided by an observation schedule that focused on seven aspects invoked from CRT. Aspects focused on included: descriptions of the physical room arrangements; aesthetics of the setting; evidence of culturally relevant literature; statements of cultural affirmation; instances of culturally relevant practices and strategies; evidence of interaction 
of the teachers with all cultural groups and lastly unanticipated events with cultural significance.

Data from observations were triangulated with four semi-structured interviews with the two science teachers purposively sampled as key informants (Cohen, Manion, \& Morisson, 2017). These two teachers were the only ones teaching grade eleven science classes out of the five teachers in the science department.

Data analysis proceeded from categorisation, thematic analysis, and node generation in a process of data reduction making connections and establishing patterns between concepts to develop theories (Miles \& Huberman, 1994). Analysis ended with interpretation and descriptions conducted qualitatively in line with the conceptual framework (CRT) and literature (Bogdan \& Biklen, 2007).

\section{Findings}

Research findings have been divided into two, that is, teacher experiences in their diverse classrooms as observed (Beyond words) and from interviews (In their words). In Beyond Words, observations presented are not exhaustive of all observed but those I considered in analysis as having utility in this research.

\subsection{Beyond Words-Observations in the Diverse Classrooms}

During the first phase of data collection, I observed Ms. Charles' (a veteran Asian female teacher) and Mrs. Visser's (an experienced white female teacher) grade eleven science classes. Ms. Charles' register had thirty-seven learners and Mrs. Visser's had thirty-one. At WHS learners were expected to line up before they entered the classroom - Why? This was the tradition, so I was told. On my first visit to Ms. Charles lab, I noticed that Indian learners with a few black learners (I later observed that these black learners were the ones who sat in the front row) had already lined up, while close by were white learners who stood out of line but directly in front of her door. Beyond the Indian line stood a cluster of black learners chatting, Ms. Charles came out of her lab and exclaimed to the chatting black learners "Why are you all standing like that, look at these learners waiting for me" (as she pointed to the Indian and white learners). She continued to mention that they "were disrespectful and arrogant and needed to learn proper manners" after which she declared that they were to wait until she had called them in. She allowed the rest in and they occupied the tables at the front. She proceeded to close the door, but then hesitated (maybe because I was there, but I later learnt that it was policy for learners not to be kept or sent out of class for whatever reason) and then brashly called them in and warned them that if that happened again she would not allow them in.

After the learners had entered the lab the following exchange took place: The class began with a roll call, as Ms. Charles called out names the learners responded "Yes, ma'am, or present ma'am". Ms. Charles called out "Rick", and one Indian learner said, "He is bunking" A black learner from table four queried how he knew he was bunking to which Ms. Charles remarked, "Don't talk to my learners like that, he was talking to me, if you have anything to say raise your hand. Now stand up and tell us where he is". To which the black learner responded, "No ma'am all I'm asking is how he knew he was bunking?" Decisively, Ms. Charles ordered, "Now be quiet if you don't have anything better to say". Rumbling in undertones the learner sat down.

Regarding the cultural aesthetics of the classroom settings there was no visible expression of celebrating culture and cultural diversity but bare walls and working surfaces. Tables had a lot of graffiti, mainly learners' names and the year in which they had sat in that spot. Absence of significant cultural aesthetics extended to reference materials with learners having a standard science textbook and some Indian, white and a few black learners had another revision guide that was sold at the school. These reference books seemed intensively factual and Ms. Charles frequently referenced from them.

On my first visit, Ms. Charles' delivered a lesson on the breathing process. Using a model, she demonstrated the breathing mechanism after which she lectured and wrote notes on the board, which the learners took down in notebooks. Whilst demonstrating breathing four black learners from table five moved over to table four and three as they were captivated by the demonstration. After the demonstration of the breathing mechanism the black learners retreated to the back and were engrossed with their phones. The teacher took notice of this but kept on with her exposition till the bell rang for the end of the lesson.

Mrs. Visser was teaching the same topic during my first observation visit to her class. However, her approach was slightly different with extensive use of the question-and-answer technique in tandem with intensive writing of notes as she explained further. The lesson ended prematurely after approximately fifteen minutes. Two prefects came into the classroom requesting learners who wanted to donate blood to proceed to the hall. Three white and two Indian learners from the front and second row picked up their bags and left. After the departure of the blood donors Mrs. Visser suspended the lesson and asked the remaining learners to work independently. Most learners closed their books and started chatting or reverted to their phones. Five Indian learners joined Mrs. Visser for 
informal conversation. Black learners formed two large groups at the back and engaged in conversation whilst sharing files on their phones.

The second observation visit coincided with Ms. Charles' scheduled practical. She announced the working groups. As the learners proceeded to workstations they begged her if they could work with peers to which she relented. Re-grouping became racialised except for two groups, one with two Indians and one black learner and the other with one Indian and two black learners. This observed grouping extended racialised spatial distributions beyond sitting patterns. Ms. Charles presented an overview of the practical and gave a worksheet on the methods. As groups completed the worksheet she moved about assisting them. Her conduct seemed contradictory as learners were being assessed for independence. Ms. Charles showed amazement at how black learners at the back were working and could not stop complimenting them.

During this second observation session, unanticipated events with cultural significance occurred as recorded. These incidents revealed the relational aspects at work in the classroom.

Assembly finished at eight o'clock. Learners arrived for class and Ms. Charles closed the door five minutes after the bell. Five learners arrived late, four black and one Indian. The Indian learner proceeded to open the door without knocking, handed Ms. Charles a note and was admitted. (With nobody aware of what was written on the note handed to Ms. Charles by the Indian learner, there was a risk of the incident hinting differential treatment of learners in her class). The four black learners remained outside. After fifteen minutes Ms. Charles addressed the late learners. "Why are you so late?" "Tell me you did not hear the Principal at assembly telling you to return immediately to class?" She allowed them in, handed them the practical worksheet and they made their way to the back of the class. "Put yourself into a group like the others, work on that and submit the completed work at the end of class" she instructed. She did not explain the practical as she had done prior to the late learners' entry.

Whilst in the same class, a black learner was caught bunking this class at the far end of the field. He informed the prefect that he was afraid to attend class because his work was not up to date. However, as per school policy he was escorted to class. On arrival Ms. Charles was irate and remarked "I will not have him come into my class at this late hour and disrupt a perfectly good practical. I think we can manage without him". She told him to stand outside for the duration of that lesson (Observation visit 2)

During my third and last visit to Ms. Charles' class, two unanticipated, culturally significant events occurred. After writing the word 'Respiration'- on the board she asked learners to suggest definitions. Learners at tables one and two were actively brainstorming making suggestions which the teacher put on the board. Black learners at the last two tables were restless and not focusing on what was happening. They intermittently conversed and she had to constantly call on them to be part of the lesson. At one-point Ms. Charles shouted, "This work is important, it will be there in your test and exam, if you don't get it you will fail". However, this did not deter them as they would focus for a while and later were disengaged.

Whilst this was going on, a black learner sitting at the back of the class was frantically typing on his phone. Ms. Charles ordered him to surrender the phone to which he refused vehemently, "It's my phone ma'am, I can switch it off, but I cannot give it to you". Ms. Charles gave him an ultimatum, "Either you surrender the phone, or you are out of my class!" The black learner put his notebook back into his bag, quietly stood up and walked out of the classroom. Ms. Charles continued with her teaching seemingly distressed but giving no attention to what was happening at the back tables.

On the second visit, Mrs. Visser's class took about five minutes to settle as she moved some black male learners from the back two rows and swapped them with some black learners from rows two and three and did the roll. She began her lesson by asking learners to take out their workbooks. Of the black learners she had moved upfront four did not have their workbooks and she instructed them to leave class to borrow from Ms. Charles' class. As the black learners were leaving the class a white learner was busy going through his bag and upon inquiry Mrs. Visser was informed that he seemed to be missing his workbook. Mrs. Visser instructed him to sit next to a learner in front of him and share as she proceeded with the lesson. By the time the black learners returned she had already gone through the introductory part of the lesson.

Midway during this lesson there was a strong smell of marijuana in the class. A black girl from table three alerted Mrs. Visser who stopped teaching, walked to the back row to a black learner who seemed fast asleep with his head on the desk. She asked him to wake up, but he kept his head down. Eventually, he raised his head, but his eyes were blood-shot. "Did you smoke dagga?" she asked the learner to which he responded, "No". Then she remarked, "Then why are your eyes so red?" A mini quarrel ensued as she insisted he had smoked dagga. The white male teacher from next door was called and also alleged that the learner was high on drugs. The learner was sent to the Deputy Principal for a drug test. I later learnt that the results were negative and the Deputy Principal later informed 
Mrs. Visser that the learner had an after-school job and suffered from sleep deprivation. It was confirmed the smell came from the staff quarters located behind the classroom.

The last observation session in Mrs. Visser's classroom yielded three significant observations. Firstly, out of the thirty-six learners that were supposed to be present in her class, six were absent who were all black learners. Secondly, Mrs. Visser had a tendency of standing by the door as learners came through and did uniform inspection. On this day she had the following exchange with one of her black female learners, "Why have you not removed your braids? Didn't I tell you last week and we agreed that over the weekend they will be out." The learner responded, "My mom says she will do it this weekend because she was working and didn't have time." "That's a poor excuse, you girls just don't listen," remarked Mrs. Visser. I observed she said nothing to the Indian girls who had their hair highlighted.

The last significant, unanticipated event occurred during this same lesson. The lesson had been flowing and learners seemed engaged during the question-and-answer session, however, Kevin who was seated in the fourth row was not paying attention and Mrs. Visser asked him a question "So tell me Kevin, what is the difference between respiration and perspiration?" Kevin was clueless. I observed that the question seemed out of context and aimed at embarrassing the learner. During this exchange, one black learner sitting next to Sbu mumbled something directed at Kevin and some learners laughed. Mrs. Visser was agitated and ordered them to go and stand at the back until they had told her what it was they were laughing at. They all grudgingly obliged but murmured that they were being punished for nothing. As they stood at the back which is where I was seated, I learnt that what the learner had said was "There you go wise guy, caught flat-footed". Whilst Mrs. Visser was dealing with Kevin and his peers one black learner in concurrence with the Indian learners from the front row suggested that she kicks them out as they were not in school to learn and she could save her energy. Mrs. Visser did not address these learners' utterances.

During observations hints of acknowledgement of diversity occurred twice. During the first observation visit, Ms. Charles had asked the name for lungs in Sotho (one of the local languages). A similar event occurred in Mrs. Visser's class during the second observation visit, whilst teaching kidney diseases she asked, "Can one African learner tell us how the African culture explains kidney stones as opposed to the medical explanation?". Implicit in the statements made by the teacher was the notion that all black learners were African, and their episteme were oppositional to scientific explanations.

Whilst other scholars have inferred differential treatment of learners in diverse pedagogic contexts (Jansen, 2004), the school demographic skew in all these studies was against black learners, which made findings in this study different because at WHS black learners were the demographic majority despite being a cultural minority. This study captured overt differentiation, inequitable treatment of black learners as well as intra-racial differentiation based on conformity. The overt and inequitable nature of these artefacts was exemplified with incidents in Mrs. Visser's class in which learners had to go and fetch learning materials; the treatment of late comers by Ms. Charles (perhaps the Indian learner had a valid excuse), and late admission of black learners into class and asking them to proceed with the task without any guidance; Ms. Charles focusing on teaching the front row learners, whilst those at the back continued enacting in ways that limited their learning opportunities; Mrs. Visser picking on the black learner when dagga was smelt; questioning the black girls and excusing the Indian girls with regards to hair compliance and Mrs. Visser stopping the lesson when a handful of learners had gone for the blood donation. I am of the view that the learners who left were so few that it may not have warranted Mrs. Visser to adjourn the lesson unless the teacher perhaps thought it not worthwhile to continue teaching because the front learners who participated and complied the most had left. The striking thing with the last observation was that on my last visit to her class, six black learners were absent, but the lesson continued.

The other significant observation pertained to the relational aspects of the classrooms. Desegregated classrooms have been portrayed as peaceable, with teachers having free reign on all aspects of the classroom and black learners being docile. However, observations in this study seem to point to conflicted pedagogic settings with black learners not enacting like docile victims broken by the teachers' authority. The observations showed that classrooms were far from peaceable with teachers in a dither and discombobulated as they tried to make black learners subservient.

In terms of pedagogy, observations were of a highly centralised curriculum. The bare walls, standard textbooks and observed transmission pedagogical methods devolved all attention on the teachers. The teachers through observed pedagogical dispositions and enactments made themselves the centre and sole determinants of all that happened in the classrooms. Seemingly within their disposition was single-mindedness informed by the notion that they had a job to do. Standard textbooks and workbooks compounded this approach because they seemed to put everything 
and everyone on equal footing. It is for this reason that standard textbooks have been indicted as incompatible with responsive context sensitive curriculum (Malcolm \& Alant, 2004). The observable impact of these pedagogical approaches was their failure to capture and sustain the attention and interest of those on the fringe.

Closely related to the pedagogical observations was the seeming essentialisation of black learners. As Ms. Charles asked black learners to name lungs in Sotho she misrecognised black learners and their sociocultural diversity. Perhaps her question was because Sotho is the language spoken by the majority of black people in the area in which WHS was located. However, the exclusionary potential of such enactments remained problematic as it alienated black learners for whom Sotho was not their language, particularly in the context of xenophobia. It became my view from these observations that such oversights on their part could be interpreted as essentialistic and alienating by those whose language had not been acknowledged. This finding pointed to teacher enactments bordering on denial of difference, essentialist stereotyping and culture-blindness.

The observations above captured what was going on in the integrated pedagogic setting. However, it was inadequate to draw inferences from such without establishing the value-system of the context. It was in the context of the latter that teacher experiences were solicited via semi-structured interviews.

\subsection{In Their Own Words-Teacher Experiences with Diverse Learners}

Data analyses resulted in the following broad themes vis-à-vis teacher experiences in diverse classrooms: experiences of who the learners were; experiences of interaction with diverse learners; experiences of teaching diverse learners.

\subsubsection{Identity Matters-Experiences of Who the Learners Were}

In the first interview teachers were asked to describe their learners. Findings were that race continued to have pertinence as a diversity and demographic signifier as captured in the following excerpts:

If I'm describing them to somebody, then it's by race. I have three Indian boys in my class who sit together, then seven white boys and 10 black boys and no coloureds...Then, it's boys and girls ...gender helps me when I'm calling the register. It doesn't worry me that much. (Mrs. Visser, Interview 1).

They vary as I said they range from different race groups, so its Black race group, Indian race group and White race group. There are a few Coloured learners that I see but basically it's differences by race. (Mrs. Visser, Interview 1)

Findings were that the essence of diversity and differentiation was skin tonality as well as surface elements. The centralisation of race negated the essence of variants of humanity beneath the surface elements. This surface level understanding of diversity hinted at teachers' limited understanding of culture and its potency in pedagogical settings as confirmed by their responses to the possibility of using culture to describe their learners:

Well, culture or race, so what do you mean by culture? You know like we say Indian children, for example, I find Muslim children are different from Hindi children, Indian is that cultural? You see they are the same race, Indians, but they are different, they have different religious upbringing (Ms. Charles, Interview1).

Different backgrounds, different ways in which to practice lifestyles, the way you practice religion. Different types of upbringing. Different ways your family lives are run. I think that's culture and people are culturally different. That's it. (Mrs. Visser, Interview 2)

It seemed the educators could not conceptualise culture beyond superficial elements, an aspect which seemed to affirm the vestigial insularity and reductionism of colonialism and segregation. This limited understanding of culture was also coupled with limited knowledge about the learners:

Maybe because I don't know where they are coming from, exactly what their experiences are. I know when we did the ecology study, I would say, you have to find a river near your home, but it must be safe, then some of them said there is nothing...or take a patch in your garden...we don't have a garden they would say, that sort of thing... (Ms. Charles, Interview 1).

Teacher experiences of culture as synonymous to race and the consequent differentiation of learners based on the superficial governed their referent system and sustained essentialistic discourses. The latter involved the construction of black people in forms that were deficient, pejorative and archaic. Whilst responding to a question on their experiences with teaching in a multicultural context like WHS, Ms. Charles pointed out some of her challenges. Firstly, she contended that "Black parents were dishonest, and they were not as aware of the school rules as compared to white and Indian parents because they were illiterate". Also, they (WHS) had stopped giving major homework "because in most black homes there were no tables and comfortable furniture for learners to work comfortably". Worse still from her experience black learners "don't get home till it's extremely dark in 
winter...they have many more chores than any other kids...So for the black learner, homework, it's you do it when you've done your chores. When you've fed your little sister or whatever... (Ms. Charles, Interview 1). Affirming this purview, Mrs. Visser (Interview1) posited "Black parents were not involved in the academic welfare of their children because they were too busy with other activities and education was not a priority for them, which was different from Indian parents". These expressed experiences made it easier for me to understand why Ms. Charles blamed black parents for black learners' disengagement since, "they are not as aware of the school rules and what they should be expecting from school" (Interview 1). At a cultural level these expressed experiences promoted assimilation as rationalised, "It must be very hard (for black learners) because of their background and then this high standard of expectations (WHS and teachers) but things are changing as they are adapting, those kids we touch". The experience explained Mrs. Visser's tirade at black learners for their reluctance to "take advantage of opportunities opened up for them by being in schools like WHS" (Interview 1). It seemed the teachers took it as their responsibility to manage and transform black learners into conformity with their traditions.

Within Culturally Responsive Teaching (CRT), black learners are black, but they are not black people. As such, teachers ought to differentiate and attend to their black learners as learners and not as black people. Due to notions anchored in racialised identity, it seemed difficult for teachers to differentiate their black learners from the black collective and resultantly expressed their sedimented essentialised notions of black people on the learners. It was a common phenomenon amongst the science teachers to try to motivate black learners by mentioning the presumed deficient conditions from which they hailed. As Mrs. Visser remarked, culture was instrumental in her teaching when she used "their upbringing, their hardships, their parents' sacrifice in sending them to WHS" as a motivational tool (Interview 2). It was her opinion that black learners needed to give their best in lieu of gratitude for attending a better school. In line with this propagated notion black people assumed a lower order social identity and were experienced as socio-economically deficient. What was problematic with this notion was that it was more than eighty percent of black learners at WHS were children of property holders of Wingate, which was a middle-class suburb. These learners were not experiencing hardships as assumed and were not necessarily being bused from the townships as presumed. These deficit notions demonstrated how much learning the teachers needed about their black learners, their families, life stories and everyday realities.

\subsubsection{Agony at the Deep End-Experiences of Interaction with Learners}

Teachers' professed negative experiences as they interacted with urban black learners. Wary of the racialised locus of their challenges the teachers agonised in expressing their experiences with black learners and constructed them using sanitized markers. For Ms. Charles, black learners were "trouble" because "they need more help ... all the time..."It's hard...the black kids seem less interested...they kind of lose focus..." (Interview 1). Not only were black learners' trouble but also "difficult" to teach since their "pronunciation and the grasp of the language" was difficult to comprehend (Ms. Charles Interview 1). Mrs. Visser affirmed the teachers' negative experiences and tried to explain the disparate environment, "I have noticed that they seem to understand or prefer black educators than educators from other race groups" (Interview 2). Mrs. Visser's further rationalised black learner dispassionateness as she remarked "because they believe that the person from another race group is probably dumb or doesn't understand them or is just picking on them because they are black, maybe they feel that we don't know their circumstances. On being asked what she had done about this, she remarked trivialising the sociocultural in classrooms "Do we have to do anything? That's my question. Do we have to do that, do we actually have to say we know your circumstances, haven't we all been through some circumstances?" (Interview 2). Affirming the trivialisation of the sociocultural and rationalising their approaches in the classroom she concluded:

Maybe they just feel we don't understand them being Black. I mean there is so much more to being black, they play the race card all the time. For some of them, they just feel it's (race) a trump card. It's like, it's now time for me to play the race card, it's now time to get some pity for what I've done. I think they need to take responsibility for their actions and put colour aside (Interview 2).

Within CRP, teachers use their social knowledge about their learners and their social consciousness to inform practice and make classrooms communitarian. On this pedestal teachers sacrifice dictates of rational efficiency, prescripts of the discipline and striving for academic excellence through accommodating their learners' life stories in fluid multi-lineal relationships. CRP hinges on teachers knowing their learners' interest, their socio-political self and the integration of these in pedagogy. However, teachers' interaction experiences at WHS alluded to engagements that were conflicted and unproductive, "It's like you are policing them around every day, all the time and they are irritated because you are policing them and you are getting irritated because you are not getting what you need from them" (Ms Visser, Interview 2).

The fact that the teachers were unaware of their learners out of class life exacerbated this charged environment. 
When asked about their learners' interests, Mrs. Visser was vague and superficial "Some of them yes, sports, phones, some going out to clubs, some of them alcohol" and when probed on whether there was any connection between their interests and her teaching, her answer was concise "No, not actually" (Interview 2). The teachers tried to explain the disconnect between their teaching and learners' interests, "Maybe because I don't know where they are coming from, exactly what their experiences are." (Ms. Charles, Interview 1). The science teachers rationalised and defended their shortcomings in developing a personal and socially functional relationship with black learners in their classes in three ways. Firstly, it was due to large classes, and then the need for academic success hence the focus on what mattered - academics and then apportioned blame on the urban black learners:

No information is forthcoming as compared to other race groups...I don't know, they (black learners) are much more private, yes there is a concern, why? Do they feel inferior? Do they feel it's their home, they don't want to be known? (Mrs. Visser, Interview 2).

As Mrs. Visser made the statement above she was oblivious that most black learners at WHS were their family's first generation in this school, as opposed to some white learners whose parents she had taught. What emerged from the abstractions of the teachers' experiences was either their incapacity or reluctance to invest in relationships with their black learners. In terms of incapacity to structure for CRT it seemed the status quo relieved teachers of the anxiety of planning for diversity. By creating impersonal non-communal classroom spaces, the teachers averted the rigorous engagement necessary for multicultural teaching. Secondly in terms of it being reluctance, their expressions seemed subtle coercion for those who were culturally different to assimilate, so as to enjoy proximity to the teacher as posited, "They are not comfortable with me and so they just stay away, but honestly, I tell everyone in class to come for help and that I'm available to help, but they just don't come" (Mrs. Visser, Interview, 2). Converse to CRP tenets from which fluidity in relations promoted academic excellence, it seemed currency for teacher-learner interactions was dependent on black learner assimilation and yield to the teachers' prescripts.

Lastly, there seemed to be a domination of the traditional teacher mysticism by which the teachers rendered themselves inaccessible and as such remained a mystery. From the mystique the teachers continued to control and force compliance without any need for communication. Thus, in the latter sense this positioning had a paradoxical utility in rendering teachers the ability to enact as free self-governing agents in a democratic context.

\subsubsection{No Time to Waste-Experiences of Teaching Them}

The spirit and approach of teaching experience professed by the teachers in this study seemed poised at content mastery. The oddity was that teachers operated this way whilst fully aware of the limited impact of their approaches as they affirmed "They need me to bring in feelings and discussion, so they are not bored with the subject and they are just hating and doing it for the sake of doing it. They have to like it, they have to find something enjoyable in it" (Ms. Charles, Interview 1). It was a critical finding to note that teachers were fully aware of the utility of investing in affect despite insisting that learners had to take it as presented. The teachers acknowledged the existence of learner apathy and blamed it on the learners:

"Some of them are just lazy. They just wanna get the day over with. They don't wanna be here, their attitude speaks tonnes, work not done, homework not done. They forget they are writing a test. So, it's that lackadaisical attitude of theirs (Mrs. Visser, Interview 1).

Within a CRP framework, teachers are expected to have a disposition for constructivist approaches by which they structure the pedagogic setting on the lived experiences of all learners. Through deliberate democratisation of the learning process teachers open the pedagogic setting for learners to take charge of their learning. Through fluid teacher-learner relations communication is multi-directional, thus, whilst maintaining high expectations teachers allow learners to be themselves. Other than using the carrot or the stick, teachers within CRP search for ways to trigger and direct intrinsic learner motivation inclusive of presenting learning situations that arouse critical consciousness whilst providing opportunities for autonomy and competence.

Contrary to CRP aspirations, pedagogy at WHS was prolonged espousal and transmission. Science teachers were the epicentre of classroom discourse and alluded to this. Observations were that they were responsible for setting expectations, prescribing activities, procedures and predilections that prevailed. Teaching in both classrooms was uni-linear, punctuated by intermittent callouts of learners' responses. More than the aspect of the methods, the experience that the science teachers were the ultimate arbiters of the curriculum led to the negation of learner culture, its role in pedagogy, and fuelled stereotyping and essentialist perspectives of culture. For example, from the interviews the teachers acknowledged the pedagogical potency of learner culture, still maintained bare classroom walls and delivered content the traditional culturally sterile way. 


\subsection{Discussion of Findings}

Findings above foreground several things and in the ensuing discussion, I highlight the key findings from the science classrooms at WHS.

With regards to the cultural terrain, findings were that the context was not culturally neutral. Other than not being culturally neutral, the context was also not a culturally-receptive space in which other cultures could carve a niche and allow participants in them to transact their capital in productive ways. The context was predominantly structured and reflected the teachers' culture. Structured around the teachers' culture, the context assumed dual instrumentality: that of allowing only the teachers and those who embraced their culture to transact and profit whilst at the other end denying those who were culturally different from exchanging and transacting their cultural capital. Constituted in the way it was, the context came across as mono-culturally oriented and hence, non-responsive to diversity that came with desegregation.

This work is not an indictment of my colleagues' work, whom I believe work so hard and whose intentions to provide optimum opportunities for learning, I do not doubt. However, Milner (2006) posits "But good intentions are not enough" (p. 79), there is need for making the treacherous, conflict-ridden integrated science classrooms more productive. The common strand that traverses CRP is a compelling argument for movement beyond the self-imposed restrictions that confine us to our created worlds to a viewing of spaces that impact on schooling as an integral part of the teaching endeavour. As found in this study the transforming science classrooms are a necessary space that we all need to explore, understand and embrace. The cultural terrain in desegregated classrooms here represented by WHS was characterised by dynamic agonism generated from the perceptive frames premised on divergent fundamental assumptions. Attempts at making the contexts more productive need a rethinking and reframing of science education in order to help all parties involved manage their assumptions in ways that will limit or even eliminate enactments that limit opportunities for teaching and learning. However, movement into this space is a move beyond traditional classroom discourse. It is a move that involves negotiation of traditional constitutions of teachers and teaching. Such a change is a radical and revolutionary shift in practice. In conflict-ridden contexts, as the one studied, such a shift cannot proceed without carefully considered negotiation, lest interventions are misconstrued as further violations and exacerbates the situation. It is with this understanding I aptly included "negotiation" in the title of this work.

Negotiation as applied in this work is both an inter-relational discourse as well as reflexive engagement within oneself, having a two-sided quality, looking both inwards and outwards. It can be argued that the whole purpose of negotiation is not to facilitate the evolution of a common narrative but a reductive transformation of agonism to enable parties in the pedagogic setting co-create insights that alleviate their defend-attack enactments. I hasten to point out that such negotiation must be knowledge-based, particularly the holistic knowledge of the learners. From the discussion above an emerging notion that we need to know and embrace is that teaching is more than an academic endeavour, but a socio-political calling. The porosity and fluidity of the socio-political space therefore necessitates that teachers become learners of their learners to be able to innovate in meaningful and productive ways. In this context teachers practice disciplines, Senge (1994) regards a discipline not as "enforced order" or punitive technologies, but a "body of theory and technique that must be studied and mastered to be put in practice" (p. 10). Implied in this conceptualisation is the notion of discipline as a developmental path for acquiring certain pragmatic competencies through practice. Thus, for teachers to practice a discipline entails creating learning atmospheres and holding diffuse ever-evolving mental models. Such mental models serve as precursors of practically-nuanced epistemic advancement. What we need to know is that in such a state, teachers as learners cease to be separate from the worlds of their learners and begin to actively interrogate how their actions may be contribute to the socio-political challenges that they experience. In this state teachers become enmeshed in learning cycles of their learners' cultures.

The challenges that emerge from the research findings and discussion are how can teachers learn their learners' sociocultural epistemes in classrooms to better serve them? In conducting this study, I entertained the possibility of teachers researching their learners' webs of meaning and instituting accommodative adaptations to increase learning opportunities for all learners. What was needed was a tool to facilitate these localised sociocultural studies.

\section{Negotiating the Cultural Terrain-The LEAP Model}

From research experiences I propose a learning model that can be adopted as teachers practice disciplines. Cognisant of the porous and dynamic nature of culture this model is cyclic providing for continuous learning cycles. The cyclic nature of this model invokes the spirit of practicing disciplines which are premised on constant and consistent lifelong learning. I have named this model the LEAP approach and structured it as in Figure 1 
below.

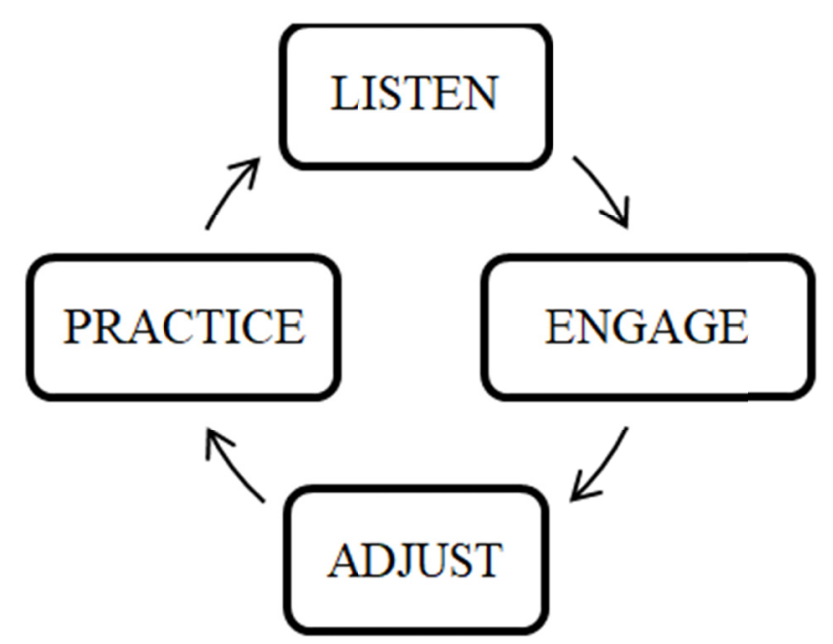

Figure 1. The LEAP model-a culture-learning tool

In the following discussion I explain the model as a tool available for those who may find themselves in the cultural crucibles.

\subsection{Listening}

The first step in learning our learners' culture should involve capturing artefacts. I have used the term listening to symbolise the nature of the process of capturing what unfolds and physically manifests in a classroom. In his work The Lost Art of Listening, Nichols (1995) conceptualises listening as having two purposes: information intake and the privileged witnessing of another's experiences. Applied to this model, this view of listening has two implications. Firstly, it speaks of the process of listening and secondly, the posture of the listener.

As a process, listening is an active process associated with paying attention, giving cognisance, being prompted to act, giving due recognition, taking interest or an enduring immersion in another person's experiences. Listening as a process in this model therefore involves the raising of the teacher's antennae to enactments and words, spoken and unspoken in an attempt to dig and capture what is being conveyed. It is the sensory legitimation and recognition of manifested artefacts.

In terms of posture, the teacher's enactment of listening is premised on being a witness and not on evaluation. Humans connect with each other as what Kohut (1971) has termed self-objects. Self-objects are empathetic others who are for us and relate to us without any ulterior malicious motives. Assuming this posture, teachers empathetically escape their isolationism, suspend their mysticism and enter into the realm of their learners' experiences. Listening therefore requires both effort (as a process) and is intuitive (as a posture) and is poised at gleaning others' webs of meaning.

\subsection{Engagement}

The second stage in the learning cycle is engagement. After gleaning the artefacts and having suspended sedimented assumptions, the teacher needs to establish the learners' culture or basic assumptions. Whilst most anthropological frameworks establish cultural understanding by inference, in this model it is important for teachers to solicit meaning from the enactors through dialogic engagement. Dialogic engagement involves what Senge (1994) conceptualises as a "genuine thinking together" ( $p .10)$. This process involves the teacher creating group or individual opportunities for discussing observed artefacts. Dialogic engagement allows a broader meaning-making process through which insights not obtainable individually, are obtained. In such engagements there is no winner as the focus is on building self-sustaining, mutually beneficial learning communities in the classroom. From dialogic engagement based on mutual respect, trust and fortified relationships built in listening, learners disclose their cultures. Learners yielding and opening about their true self may take time and will involve prolonged listening. However, the reward is bi-pronged: it results in the teacher developing a cultural understanding of the learners and secondly, it creates communal classrooms based on a shared genuine vision of an improved co-created context. Thus, through dialogic engagement there is an excavation of cultural meanings through enrolment, 
relationships and not power or enforced conformity.

\subsection{Adjusting}

The third stage is adjusting. After dialogic engagement, the teachers adjust their basic assumptions. This is the most difficult stage as it involves transformation of basic assumptions in the guarded domain of affect. It is a stage that is associated with psycho-emotional dissonance and a lot of anxiety as the teacher breaks out of the mould of traditional discourse and begins to entertain other innovative possibilities. Insights gained in this study point to teachers overcoming the possible trauma associated with this stage on the potential reward of adjusting and the tragedy of complacence. It is important that at this stage after committing to listen, the teacher would have also committed to empathetically sacrifice self for the learners. Implicit in the power of empathetic listening is the overcoming of the inertial resistance of assumption suspension or transformation. Adjustment strengthens relationships and generates assurances about connectedness and humanness, attributes which will compel mutually beneficial rapport.

\subsection{Practice}

The last stage is practice. In this stage the teacher creates the learning environment that addresses the learners' socio-cultural needs. As the teacher practices, new intervention waves are set up through listening to learner artefacts. In this way practices become associated and feed into another listening cycle and the learning cycle continues.

My hope as I propose this model is that LEAPs can be made in ways that learners' reality is integrated into the classroom. I acknowledge that at national and provincial levels of government policy frameworks exist and this tool can contribute to the translation of the policy yearnings into reality as all our learners, in their diversity, have their learning opportunities optimised. I envisage this proposition makes CRT less abstract as teachers become responsive ethnographers in their social fields to better serve those in these spaces.

\section{Recommendations}

My recommendation as I conclude this work is that as teachers we need to acknowledge the existence of a cultural terrain in diverse contemporary classrooms. We also need to acknowledge the agency of our learners as cultural beings. As teachers we must extend opportunities for all our learners to partake at the tables of power. Invitation to the tables of power should not be done in the spirit of reparative empathy but through conscious and voluntary acknowledgement of them as cultural beings with power and agency and as critical players in the classroom. Thus, in our negotiation of the cultural terrain our role needs to change and as we reject the top-down pedagogy which evolves from the banking theory (Milner, 2006) in which we are depositors of knowledge and our learners are depositories who patiently receive, memorise and repeat. Teachers must begin to structure the cultural terrain for smoother cultural negotiations through asking the right questions and helping learners locate answers to questions and areas of interest. The creation of these communal classroom spaces needs us to be brutally honest with our learners in explaining how power is ingrained in the social fabric and how it operates and manifests. It is only from such conversations that our learners develop the ability to understand, negotiate and navigate through the cultural terrain.

\section{Conclusions}

The realisation from this study has been that cultural diversity in the classroom is both a challenge and an opportunity. It is a challenge because our knowledge and skills for effectively teaching diverse learner populations have not kept up with demographic transitions we need to serve. However, diversity is an opportunity to teach about the joy of experiencing a variety of cultures, languages, and respecting all people. The realisation and materialisation of this opportunity lie in deliberate overtures being made to generate knowledge about such contexts - hence this study. The emerging mantra for practice is Teach Less; Learn More and LEAP across cultural epistemic gaps and teach from within the learners.

\section{References}

Au, K., \& Jordan, C. (1981). Teaching reading to Hawaiian children: Finding a culturally appropriate solution. Culture and the Bilingual Classroom. Studies in Classroom Ethnography, 139-152.

Bennett, C. I. (2015). Comprehensive multicultural education: Theory and practice. Upper Saddler River, N.J: Pearson.

Bogdan, R. C., \& Biklen, S. K. (2007). Research for education: An Introduction to Theories and Methods. New York. Pearson.

Brewer, J., \& Hunter, A. (2006). Foundations of multimethod research: Synthesizing styles. Sage, Thousand Oaks. 
https://doi.org/10.4135/9781412984294

Cohen, L., Morrison, K., \& Manion, L. (2017). Mixed methods research. In Research Methods in Education. Routledge. https://doi.org/10.4324/9781315456539-2

Cruz, E. V., \& Higginbottom, G. (2013). The use of focused ethnography in nursing research. Nurse Researcher, 20(4), 36-43. https://doi.org/10.7748/nr2013.03.20.4.36.e305

Gay, G. (2018). Culturally responsive teaching: Theory, research, and practice. Teachers College Press.

Gilmour, L., Klieve, H., \& Li, M. (2018). Culturally and Linguistically Diverse School Environment-Exploring the Unknown. Australian Journal of Teacher Education, 43(2), 172-189. https://doi.org/10.14221/ajte.2018v43n2.10

Goldston, M. J., \& Nichols, S. (2009). Visualizing culturally relevant science pedagogy through photo-narratives of Black middle school teachers. Journal of Science Teacher Education, 20(2), 179-198. https://doi.org/10.1007/s10972-009-9125-z

Howard, G. R. (2016). We can't teach what we don't know: White teachers, multiracial schools. Teachers College Press.

Jansen, J. D. (2004). Race and education after ten years: conversations. Perspectives in Education, 22(1), 117-128. https://hdl.handle.net/10520/EJC87286

Johnson, C. C. (2011). The road to culturally relevant science: Exploring how teachers navigate change in pedagogy. Journal of Research in Science Teaching, 48(2), 170-198. https://doi.org/10.1002/tea.20405

Kapofu, L. K. (2019). Teacher culture and emergent context in two desegregated science classrooms in South Africa: A focused ethnography. South African Journal of Education, 39(2). https://doi.org/10.15700/saje.v39n2a1581

Kohut, H. (1971). The Analysis of the Self. New York: International Universities Press.

Ladson-Billings, G. (1995). Toward a theory of culturally relevant pedagogy. American Educational Research Journal, 32(3), 465-491. https://doi.org/10.3102/00028312032003465

Malcolm, C., \& Alant, B. (2004). Finding Direction When the Ground Is Moving: Science Education Research in South Africa. Studies in Science Education, 40(1), 49-104. https://doi.org/10.1080/03057260408560203

McAllister, G., \& Irvine, J. J. (2000). Cross cultural competency and multicultural teacher education. Review of educational research, 70(1), 3-24. https://doi.org/10.3102/00346543070001003

Miles, M. B., \& Huberman, A. M. (1994). Qualitative data analysis: An Expanded Sourcebook. Sage.

Milner, H. R. (2006). Preservice teachers' learning about cultural and racial diversity: Implications for urban education. Urban Education, 41(4), 343-375. https://doi.org/10.1177/0042085906289709

Mohatt, G., \& Erickson, F. (1981). Cultural differences in teaching styles in an Odawa school: A sociolinguistic approach. Culture and the Bilingual Classroom. Studies in Classroom Ethnography, 105.

Moloney, R., \& Saltmarsh, D. (2016). 'Knowing Your Students' in the Culturally and Linguistically Diverse Classroom. Australian Journal of Teacher Education, 41(4), 5. https://doi.org/10.14221/ajte.2016v41n4.5

Nichols, M. P. (1995). The lost art of listening. How learning can improve relationships. London: The Guildford Press.

Pai, Y., Adler, S. A., \& Shadiow, L. K. (2006). Facilitate Intercultural Learning and Academic Success. International Journal of Teaching and Learning in Higher Education, 3(23), 388-395.

Senge, P. (1994). The fifth discipline. The art and practice of learning organizations. New York: Currency Doubleday.

Van Wyk, J. A. (2002). Indigenous knowledge systems: Implications for natural science and technology teaching and learning. South African Journal of Education, 22(4), 305-312.

Vogt, L. A., Jordan, C., \& Tharp, R. G. (1987). Explaining school failure, producing school success: Two cases. Anthropology and Education Quarterly, 18(4), 276-286. https://doi.org/10.1525/aeq.1987.18.4.04x0019s

Yin, R. K. (2017). Case study research and applications: Design and methods. Sage publications. 


\section{Note}

Note 1. All names used are pseudonyms.

\section{Copyrights}

Copyright for this article is retained by the author(s), with first publication rights granted to the journal.

This is an open-access article distributed under the terms and conditions of the Creative Commons Attribution license (http://creativecommons.org/licenses/by/4.0/). 